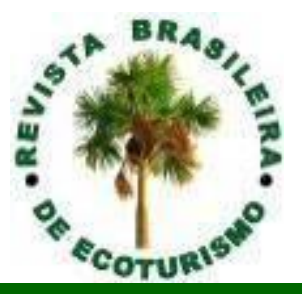

\title{
Percepções e perfil socioeconômico dos visitantes e da comunidade local para o desenvolvimento do espeleoturismo em um atrativo natural de Minas Gerais
}

\section{Perceptions and socioeconomic profile of visitors and the local community to develop speleotourism in a natural attraction from Minas Gerais, Brazil}

\author{
Hugo Rodrigues Araujo, Arnaldo Freitas Oliveira-Júnior, \\ Alexsander Araújo Azevedo
}

\section{RESUMO}

O Brasil possui um patrimônio espeleológico de grande valor científico e cultural que atrai, anualmente, um número considerável de visitantes. Entretanto, apesar das cavidades naturais existentes no país serem consideradas bens da União, na maioria dos casos, a visitação acontece sem qualquer monitoramento causando sérios danos ao ambiente cavernícola, além de conflitos com os moradores locais. Essa seria a situação esperada para a Gruta do Salitre, situada na proximidade de Diamantina, Minas Gerais, se não fosse gerenciada há quatro anos por uma ONG em parceria com a comunidade local. Porém, embora a entidade esteja desenvolvendo o monitoramento da visitação e diversas ações de conservação na gruta, ela não dispõe de um fundo próprio que garanta em longo prazo a sustentabilidade gerencial deste atrativo natural. Portanto, visando contribuir para o alcance da sustentabilidade da gestão do uso público da gruta, este estudo buscou avaliar, do ponto de vista socioambiental, a importância da estruturação do turismo da Gruta do Salitre, com base no bem-estar proporcionado para seus usuários em geral. Para tanto, os visitantes da gruta e os moradores da comunidade Curralinho, situada a menos de $1 \mathrm{~km}$ do atrativo natural foram entrevistados no período de agosto a outubro de 2013, por meio de questionários semiestruturados com o intuito de identificar o perfil socioeconômico, as percepções em relação à cavidade natural e a disposição em pagar voluntariamente pela sua conservação. $A$ análise dos resultados permitiu constatar diferenças no perfil socioeconômico e nas percepções dos grupos entrevistados. Enquanto a maioria dos visitantes da gruta possui ensino superior e recebe mensalmente acima de 3 salários mínimos, os moradores locais possuem apenas ensino básico e sobrevivem com até um salário mínimo por mês. Os visitantes em geral são provenientes de Minas Gerais, hospedam-se nas pousadas ou hotéis de Diamantina, e gastam acima de 100 reais por dia. Após o fim do apogeu da mineração na região os moradores de Curralinho passaram a enfrentar uma grave crise na oferta de trabalho na comunidade que permanece até os dias atuais. Contudo, os moradores estão mais dispostos a contribuir financeiramente para a conservação da gruta, sobretudo, porque acreditam que a cavidade pode trazer benefícios para comunidade através do turismo. Por outro lado, os visitantes entrevistados que negaram a possibilidade de contribuir anualmente para a conservação da gruta, consideram que essa responsabilidade é exclusiva do poder público. Os resultados obtidos neste estudo sinalizaram importantes informações para serem consideradas no planejamento da gestão do uso público e para o desenvolvimento efetivo do espeleoturismo local.

PALAVRAS-CHAVE: Gruta do Salitre; Geoturismo; Geoconservação; Patrimônio Espeleológico; Serra do Espinhaço. 


\begin{abstract}
The speleological heritage of Brazil has high scientific and cultural value, attracting a large number of visitorsevery year. However, despite the natural cavities of the country being considered national government areas, in most cases, visitation takes place without any monitoring causing serious damage to the cave environment, and conflicts with local residents. This would be the expected situation for Salitre Cave, located in the vicinity of Diamantina, Minas Gerais, Brazil, if not for the four years of management by an NGO in partnership with the local community. Yet, while the organization is still developing the visitation monitoring and diverse conservation actions in the cave, there is not a proper financial resource to ensure long-term sustainability of the natural attraction's management. Therefore, to contribute to the sustainable management of public use of the cave, this study aimed to evaluate the importance of structuring the speleotourism of Salitre Cave, based on the well-being provided to it's general users. Thus, the visitors and the residents of the Curralinho community, located about $1 \mathrm{~km}$ from the natural attraction, were interviewed during the period from August to October 2013, through semi-structured questionnaires in order to identify their socioeconomic profile, their perceptions in relation to the natural cavity and their willingness to pay voluntarily for the cave's care. Analysis of the results helped establish differences in the socioeconomic profile and perceptions of the two respondents groups. While most of the cave visitors have received some form of higher education and earn over three monthly minimum wages, local residents have only received basic education and survive on up to one minimum wage per month. Visitors generally come from Minas Gerais, staying in hostels or hotels in Diamantina, and spend more than 100 reais a day. After the end of the mining peak in the region, residents of Curralinho have faced a serious labor supply crisis in the community that remains to this day. However, residents are more willing to contribute financially to the conservation of the cave mainly because they believe that the cavity can benefit their community through the development of tourism. On the other hand, visitors who declined the opportunity to contribute annually to the conservation of the cave consider that this responsibility rests solely with the government. The results obtained in this study had important information to be considered in the planning of the management of public use and for effective development of the local speleotourism.

KEYWORDS: Salitre Cave; Geotourism; Geoconservation; Speleological heritage; Serra do Espinhaço.
\end{abstract}

\title{
Introdução
}

O Brasil possui grandes extensões de áreas propícias à formação de cavernas, o que confere ao país um valioso patrimônio espeleológico (KARMANN; SALLUN FILHO, 2007). De acordo com Janzen et al. (2012), os sítios espeleológicos mais relevantes do país encontram-se nas seguintes regiões: Centro-Norte de Minas Gerais, Nordeste de Goiás, Sudeste de Tocantins, Sudoeste e Centro-Norte da Bahia, Vale do Ribeira (SP/PR), Serra da Bodoquena (MS), Alto Paraguai (MT), Chapada do lbiapaba (CE) e Chapada do Apodi (RN). A partir da promulgação da Constituição Federal, as cavidades naturais passaram a fazer parte do universo dos bens naturais pertencentes à União (BRASIL, 1988).

O patrimônio espeleológico é considerado como sendo o "conjunto de elementos bióticos e abióticos, socioeconômicos e histórico-culturais, subterrâneos 
ou superficiais, representado pelas cavidades naturais subterrâneas ou a estas associadas" (CONAMA, 2004). Por sua vez, a cavidade natural subterrânea corresponde a:

[...] todo e qualquer espaço subterrâneo penetrável pelo ser humano, com ou sem abertura identificada, popularmente conhecido como caverna, gruta, lapa, toca, abismo, furna e buraco, incluindo seu ambiente, seu conteúdo mineral e hídrico, as comunidades bióticas ali encontradas e o corpo rochoso onde as mesmas se inserem, desde que a sua formação tenha sido por processos naturais, independentemente de suas dimensões ou do tipo de rocha encaixante (artigo $2^{\circ}$ da Resolução CONAMA no347/2004).

Embora existam mais de 14.000 registros de cavidades naturais subterrâneas no Brasil (CECAV, 2015), estima-se que menos de $5 \%$ delas sejam conhecidas no país. Anualmente, as informações decorrentes dos estudos e levantamentos realizados geram a inclusão em torno de 250 novos registros de cavernas descobertas em todo o território nacional (FIGUEIREDO et al., 2010).

O espeleoturismo corresponde às atividades desenvolvidas em cavernas, oferecidas comercialmente, em caráter recreativo e de finalidade turística (ABNT NBR 15503 - Turismo de Aventura - Espeleoturismo de aventura - Requisitos para produto). Nas últimas décadas, muitas cavidades naturais em todo o mundo foram abertas ao público como atrações turísticas. Brandão (2009) propôs a utilização da designação "cavernas turísticas" para as cavidades naturais que tendo passado por um processo de adaptação tornam-se acessíveis à visitação do público interessado pelo ambiente subterrâneo em toda a sua diversidade.

É importante destacar que o aproveitamento turístico desses espaços implica, necessariamente, na discussão de um elevado número de variáveis, algumas mais facilmente percebidas, como a construção de infraestruturas de acesso e segurança (passadiços, escadas, guarda-corpos, iluminação, etc.) e outras de maior complexidade, como aquelas relacionadas à gestão do uso público do patrimônio espeleológico (CIGNA; BURRI, 2000). Portanto, são necessários estudos prévios que indiquem as fragilidades (bióticas e abióticas) da cavidade, as potencialidades de uso e as zonas de uso intensivo, extensivo e de preservação integral. No Brasil, tais estudos servem para a composição do Plano de Manejo Espeleológico (PME), que define, entre outras coisas, a "capacidade de carga" da cavidade para adequar o número diário de visitantes e a duração das visitas, bem como o tipo infraestrutura a ser instalada para facilitar o acesso das pessoas (MMA, s.d.).

Contudo, o que geralmente se verifica é que o governo brasileiro tem prestado atenção pontual, apenas em algumas cavernas, seja por subestimar o potencial das cavidades subterrâneas, ou pela insuficiência de recursos e de mecanismos de gestão e fiscalização. Desta forma, a grande maioria das cavidades naturais existentes no país não possui controle ou monitoramentos de qualquer natureza, não obstante o fato de muitas delas constituírem geossítios relevantes, ao mesmo tempo frágeis e vulneráveis (FIGUEIREDO et al., 2010). 
Esse também seria o caso da Gruta do Salitre, localizada em Diamantina, MG, e que atrai grande público devido à sua beleza e facilidade de acesso, se não fosse a iniciativa do Instituto Biotrópicos, ONG de caráter científico e socioambiental, em coordenar nos últimos quatro anos o processo de estruturação da gestão do uso público local (AZEVEDO; ARAUJO, 2011). Entretanto, embora a entidade esteja desenvolvendo o monitoramento da visitação e diversas ações de conservação local, ela não dispõe de um fundo próprio que garanta em longo prazo a sustentabilidade gerencial deste atrativo natural. Se os benefícios gerados à sociedade pela Gruta do Salitre alcançam valor estimado anual em torno de cinco milhões de reais, diversos atores sensíveis do poder público e privado deveriam, em contrapartida, contribuir financeiramente para o funcionamento adequado desse atrativo turístico (ARAUJO et al., 2014).

Diante desse cenário e com o intuito de contribuir com a sensibilização da sociedade em apoiar a gestão da Gruta do Salitre, este trabalho propôsse a identificar o perfil socioeconômico dos visitantes e moradores locais, bem como o bem-estar proporcionado pelo atrativo para os seus diversos usuários.

\section{Material e métodos}

\section{Áreas de estudo A Gruta do Salitre}

Localizada no eixo da Estrada Real, a cerca de $300 \mathrm{~km}$ de Belo Horizonte, a Gruta do Salitre situa-se no Distrito de Extração (18¹6'35"S; 4332'12"O), a menos de $1 \mathrm{~km}$ de sua sede Curralinho e a menos de $9 \mathrm{~km}$ do perímetro urbano do centro histórico de Diamantina, MG (Figura 1). A cavidade situa-se em um afloramento rochoso de quartzito em meio à vegetação de cerrado e campos rupestres, cujo relevo escarpado, em forma de ruínas, proporciona uma belíssima paisagem que se assemelha a um castelo medieval ou a uma igreja construída no estilo gótico (AZEVEDO; ARAUJO, 2011). O sistema cárstico ainda abriga uma cavidade subterrânea com vários condutos, um cânion com aproximadamente 125 metros de extensão e uma dolina circundada por paredões de 80 metros de altura (BAGGIO et al., 2012). Neste momento a gruta está em processo de ser reconhecida como sítio arqueológico.

O nome da gruta deve-se a extração do salitre, que era comum na região de Diamantina, sendo encontrado nas lapas. "A extração era fácil, bastava apanhar o salitre puro e cristalizado, que se firmava na superfície das nitreiras, sendo usado para fabricação da pólvora que, por sua vez, era utilizada na quebra de pedras para desviar os rios" (SECTUR, 2010, s/p). 


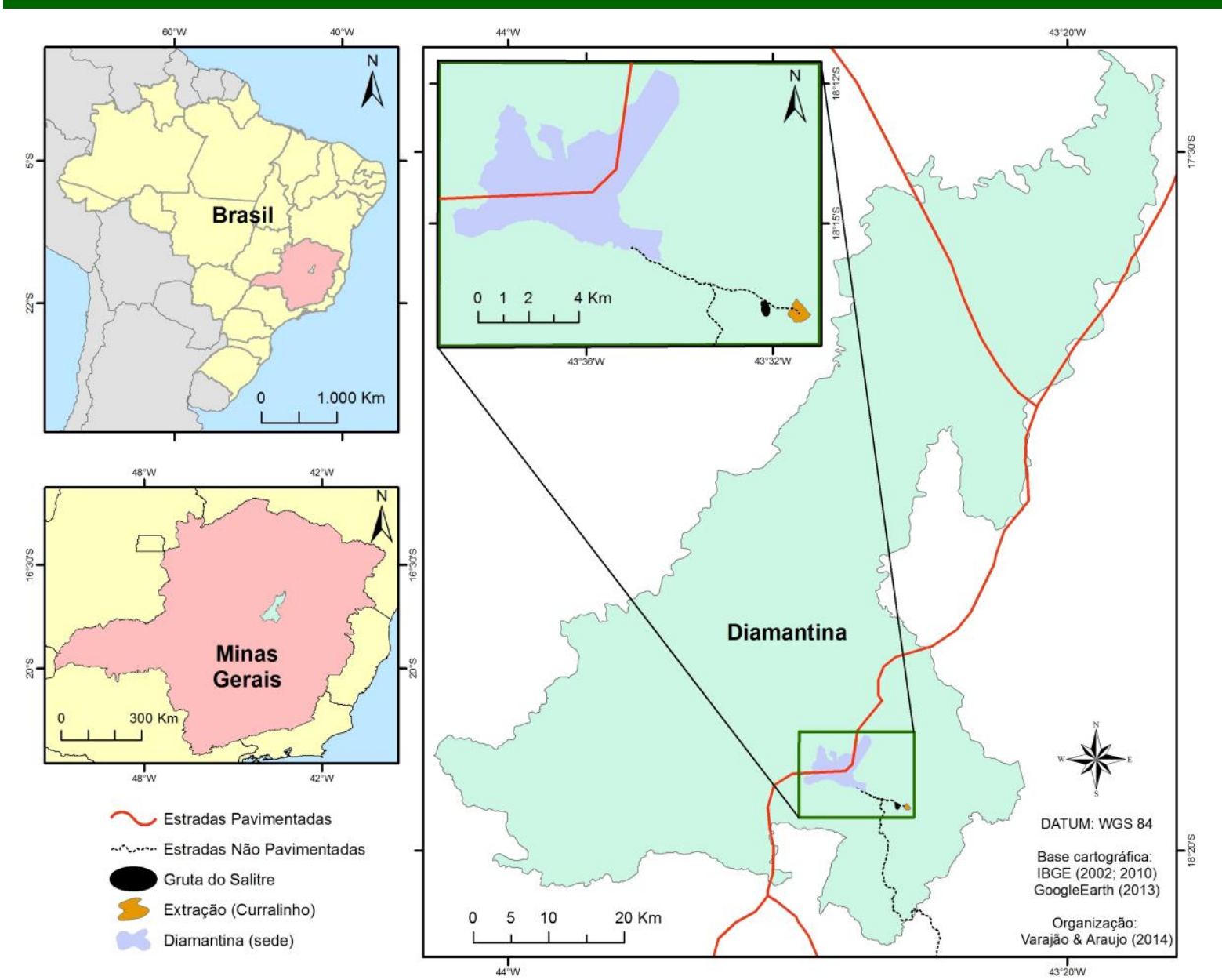

Figura 1: localização da gruta do salitre e da comunidade de Curralinho (distrito de Extração, Diamantina, Minas Gerais, sudeste do Brasil). Fonte: Araujo et al. (2015).

Figure 1: location of Salitre Cave and Curralinho community (mining district of Diamantina, Minas Gerais, southeastern Brazil). Source: Araujo (2014).

A facilidade de acesso somada à sua beleza cênica fazem da gruta um dos principais atrativos turísticos da cidade e região, sendo apontado como o segundo atrativo natural mais visitado do município em pesquisas anuais sobre o perfil da demanda turística de Diamantina (SILVEIRA; MEDAGLIA, 2014). O local é muito utilizado para a realização de práticas esportivas, eventos musicais e gravação de documentários, filmes e minisséries de televisão (ARAUJO et al., 2013). Um grande atrativo turístico local é a contemplação da imagem do mapa do Brasil visualizada no céu emoldurada pelo recorte dos paredões da dolina e o teto da lapa da entrada da gruta (Figura 2).

A relevância da gruta para o turismo regional é constatada pela grande quantidade de informações e imagens do atrativo encontradas em impressos como guias, folhetos e mapas turísticos, e também na internet através de diversos portais de turismo, blogs de viajantes, redes sociais, etc. Além disso, a gruta está sempre presente na lista de passeios oferecidos pelas agências de receptivo de Diamantina, assim como, nas campanhas promocionais da cidade histórica realizadas pelo governo e/ou empresários do trade turístico local. 


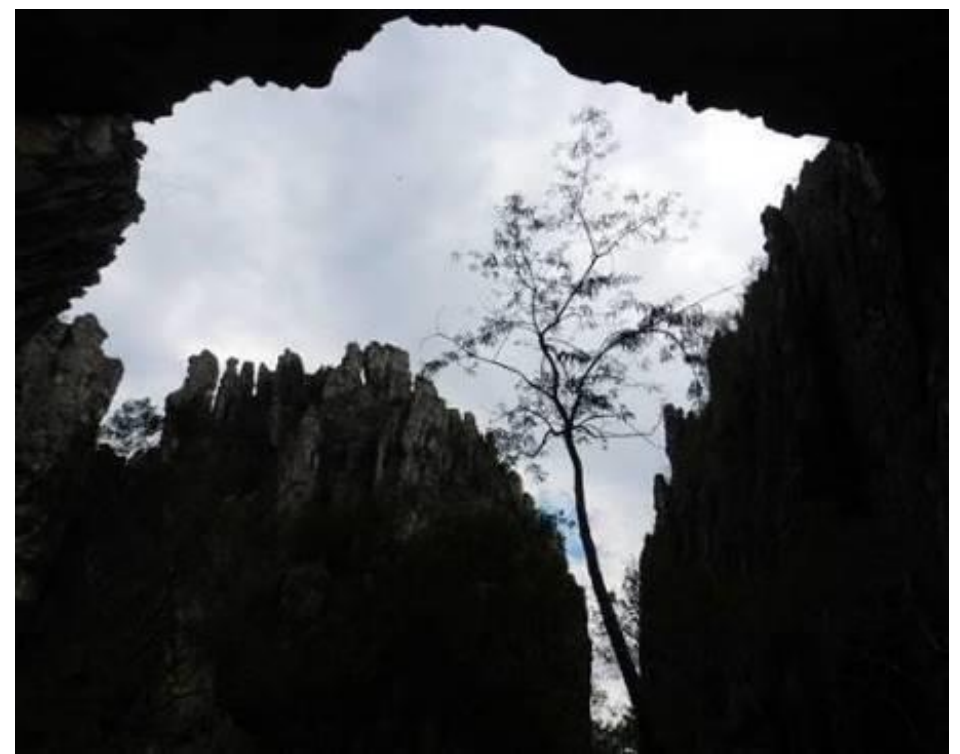

Figura 2: imagem semelhante ao contorno do mapa do Brasil, uma das principais atrações turísticas da Gruta do Salitre (Distrito de Extração, Diamantina, MG).

Figure 2: image similar to the outline of the map of Brazil, one of the main attractions of the Salitre Cave (Extraction District, Diamantina, MG, Brazil).

Atualmente, a visitação no local só é permitida mediante agendamento e acompanhamento dos gestores, monitores ou guias credenciados (moradores de Curralinho). A porção subterrânea está fechada à visitação aguardando as diretrizes do plano de manejo que está sendo elaborado e o percurso disponível ao visitante também é restrito à trilha principal conforme estabelecido no plano de ação emergencial da Gruta do Salitre (CECAV, 2011).

\section{A comunidade de Curralinho}

O povoado de Curralinho, sede do distrito de Extração, está situado a menos de $1 \mathrm{~km}$ da Gruta do Salitre e a $9 \mathrm{~km}$ do centro histórico de Diamantina (Figura 1). Suas origens remontam ao início do século XVIII, quando da ocupação dessa área por milhares de escravos que trabalhavam no leito dos cursos de água da região, inicialmente a serviço dos contratadores de diamantes e, posteriormente, pela Coroa Portuguesa que instituiu a Real Extração, em 1771. A localidade era conhecida originalmente por Curralinho, em função de um cercado para animais que ali existiu, do qual não se tem nenhum vestígio (SECTUR, 2010). Durante anos,

Curralinho foi local de pouso de tropeiros por ficar estrategicamente inserido na rota da "Estrada Real". As mercadorias vindas de Ouro Preto e do Rio de Janeiro passavam primeiramente pelo Distrito e, em decorrência disso, havia uma estrutura de comércio muito mais forte do que em Diamantina, em matéria de qualidade e preço (SECTUR, 2010).

Os casarios mais antigos de Curralinho possuem, em sua maioria, uma arquitetura colonial. As residências possuem um só pavimento, apresentam paredes de vedação em pau-a-pique ou adobe e possuem pé-direito baixo e 
telhado de quatro águas com telhas do tipo capa e bica. Porém, poucas ainda conservam estas características, pois a maioria já sofreu modificações ao longo do tempo, apresentando elementos modernos em suas fachadas (SECTUR, 2010). Apesar disso, o cenário da comunidade ainda transporta o visitante aos tempos passados de exploração da colônia, razão pelo qual já foi palco de diversos cenários para grandes produções artísticas. Na década de 70 , por exemplo, a comunidade serviu de cenário para o filme "Xica da Silva" de Carlos Diegues e, em 1995, foi escolhida pela Rede Globo como cenário principal da novela "Irmãos Coragem" transformando-se na cidade fictícia de Coroado/GO. Além disso, o filme "Vida de Menina" de Helena Solberg, baseado no livro-diário "Minha Vida de Menina - O Diário de Helena Morley", escrito por Alice Dayrell que viveu a infância em Diamantina, também teve cenas gravadas em Curralinho.

Durante o século $X X$ as mineradoras exploraram de forma exacerbada o potencial diamantífero da região e, com a queda dessa atividade extrativista, não restaram perspectivas para as futuras gerações. Alguns ainda insistem em manter a tradição garimpeira, entretanto, a maioria da população local está desempregada ou trabalhando em Diamantina. Os moradores foram aos poucos abandonando suas residências e migrando para as grandes capitais do país em busca de melhores oportunidades. Atualmente, grande parte das residências pertence a pessoas que vão ao distrito somente nos finais de semana e feriados, períodos em que o silêncio e a nostalgia bucólica de Curralinho são afetados pela presença de sons automotivos estridentes.

\section{Contexto regional}

O município de Diamantina, MG, localiza-se no Vale do Jequitinhonha, e sua sede dista aproximadamente $300 \mathrm{~km}$ da capital Belo Horizonte. Diamantina foi fundada como Arraial do Tijuco em 1713 a partir do surgimento de pequenos povoados ao redor das lavras de garimpo de ouro e diamante, em um lugar de nome Burgalhau. No século XVIII cresceu e ganhou fama devido à grande produção local de diamantes, tornando-se um dos principais núcleos da economia colonial. A exploração diamantífera que durante séculos foi sua principal atividade econômica entrou em decadência a partir da virada do século XIX e na década de 1980 começou profundamente a desacelerar, principalmente, após a criação das leis de proteção ambiental e o aumento da fiscalização (NEVES; REZENDE, 2006). Como herança daquela época, o município guarda um rico acervo histórico de exemplares da arquitetura barroca. Em 1938, Diamantina comemorou seu primeiro centenário de elevação à categoria de cidade, recebendo do Instituto do Patrimônio Histórico e Artístico Nacional (IPHAN) o título de "Patrimônio Histórico Nacional".

Diante da estagnação da mineração, a cidade passou a acreditar que o turismo poderia ser o novo vetor de sustentação da economia local e diversos investimentos públicos e privados foram realizados, especialmente, nos setores de hospedagem, alimentação e transporte (NEVES \& REZENDE, 2006). Fruto também desse esforço empreendido em prol da estruturação turística, em 1999, Diamantina foi elevada à categoria de "Patrimônio da Humanidade" pela Organização das 
Nações Unidas para a Educação, a Ciência e a Cultura (UNESCO), dando maior destaque para cidade no contexto do turismo nacional e internacional.

Atualmente, Diamantina é um dos destinos de referência da Estrada Real - a maior rota turística do país com mais de $1.630 \mathrm{~km}$ de extensão, passando por Minas Gerais, Rio de Janeiro e São Paulo - e faz parte do Circuito Turístico dos Diamantes. A cidade é bastante famosa por ser terra natal do ex-presidente da República Juscelino Kubitschek de Oliveira e de Francisca da Silva de Oliveira, a famosa Chica da Silva, escrava alforriada que era esposa do contratador de diamantes, João Fernandes de Oliveira. Além disso, também é conhecida por sua musicalidade advinda, principalmente, das serestas e vesperatas - uma autêntica manifestação local em que os músicos se apresentam à noite, ao ar livre, das janelas e sacadas de velhos casarões, enquanto o público assiste das ruas.

Os encantos de Diamantina não se restringem ao patrimônio histórico cultural. A cidade está situada a uma altitude média de 1.280 metros, emoldurada pela Serra dos Cristais que integra a Serra do Espinhaço, uma cadeia de montanhas, entrecortada por picos e vales, que se estende por mais de $1.000 \mathrm{~km}$ desde 0 centro-sul de Minas Gerais até a Chapada Diamantina, na Bahia, e, portanto, considerada a única cordilheira do Brasil (SAADI, 1995). Nas áreas mais elevadas dessa região ocorrem os campos rupestres, ecossistema caracterizado por expressiva biodiversidade e um grande número de nascentes. Uma grande porção da Cadeia do Espinhaço no Estado de Minas Gerais foi reconhecida como Reserva da Biosfera, tendo como metas a proteção da biodiversidade aliada ao desenvolvimento sustentável e ao conhecimento científico (Unesco/MaB, 2005). A região de Diamantina também faz parte do Mosaico de Áreas Protegidas do Espinhaço: Alto Jequitinhonha - Serra do Cabral (MMA, 2010). O mosaico abrange uma área de cerca de 2 milhões de hectares que se estende por 25 municípios onde estão localizadas oito Unidades de Conservação (UCs) de proteção integral e 11 Áreas de Proteção Ambiental (APA). Trata-se de uma região detentora de rica diversidade sociocultural e de extrema relevância biológica, de tal modo que a criação do mosaico tem por finalidade implantar modelos sustentáveis de desenvolvimento regional, atrelando a proteção da biodiversidade com a defesa e amparo das culturas humanas locais (AZEVEDO et al., 2009).

Outro importante propulsor de desenvolvimento para Diamantina é a educação. Desde 2005, a cidade vem se firmando como polo educacional da região após a criação da Universidade Federal dos Vales do Jequitinhonha e Mucuri (UFVJM). A instituição é constituída de três campi, sendo o Campus I e o Campus JK localizados na cidade de Diamantina (MG), abrigando seis faculdades e 23 cursos de graduação (UFVJM, 2013). Além disso, há ainda outras instituições particulares de ensino superior na cidade.

Contudo, se por um lado a Gruta do Salitre está inserida em uma região que se destaca mundialmente pela riqueza do patrimônio histórico cultural e das belezas naturais, por outro, integra o Vale do Jequitinhonha que há anos vem carregando o estigma de região miserável por apresentar altas taxas de mortalidade infantil, migração, concentração de terras, analfabetismo, desemprego, baixos níveis de renda e oferta precária de serviços de saúde, educação, saneamento básico, dentre outros problemas socioeconômicos (GUERRERO, 
2009). O Vale é uma das regiões de Minas Gerais mais pobres e estagnadas com PIB total inferior a 2,0\% do PIB estadual. A ausência de empregos fez com que os municípios desta região tornassem grandes exportadores de mão-de-obra para as culturas sazonais de café e cana-de-açúcar localizadas em São Paulo (GUERRERO, 2009). Ainda sobre a área social, há recorrentes críticas às políticas assistencialistas e à ausência de projetos destinados à formação qualificada e especializada de recursos humanos capazes de ampliar a produção de bens locais e dinamizar o mercado de trabalho e consumidor (NOGUEIRA, 2008). Deste modo, percebe-se a necessidade de iniciativas em prol do desenvolvimento local que busquem combater a pobreza e a exclusão social através da diversificação das atividades econômicas da região. Contudo, as alternativas de emprego e renda que forem criadas devem estar adaptadas às reais condições das comunidades locais e, ao mesmo tempo, comprometidas com a manutenção dos recursos naturais e culturais existentes.

\section{Coleta de dados}

Este trabalho caracteriza-se como uma pesquisa quali-quantitativa, pois objetiva avaliar a importância do turismo da Gruta do Salitre do ponto de vista socioambiental com base, principalmente, na coleta e na estatística descritiva de dados primários obtidos através de entrevistas individuais com os usuários da Gruta do Salitre e moradores da comunidade vizinha de Curralinho. Ao mesmo tempo, em relação aos objetivos, a pesquisa caracteriza-se como exploratória, pois tem como propósito preencher uma lacuna do conhecimento referente às percepções e ao perfil socioeconômico dos visitantes e da comunidade local.

Para cada grupo, utilizou-se um questionário específico semiestruturado, constituído por uma série ordenada de perguntas abertas, semiabertas e fechadas, sendo em sua maioria de múltipla escolha, formuladas de maneira a convergir a interpretação e categorizadas de forma a tentar suprir o objetivo do estudo e facilitar a tabulação dos resultados. O questionário aplicado aos visitantes dividiuse em duas etapas: a primeira visou caracterizar o perfil socioeconômico dos entrevistados por meio de perguntas relativas ao estado civil, sexo, renda mensal, grau de escolaridade, local de residência, frequência com visita a gruta, objetivo das visitas, meio de transporte, custos com a viagem, dentre outras. A segunda etapa envolveu perguntas para avaliar a satisfação com relação à gruta, buscando identificar as principais sensações obtidas durante a visita, bem como, a opinião sobre o estado de conservação e limpeza do espaço natural, disponibilidade de informações, condições de acesso, atendimento dos monitores e a disposição a pagar pela conservação da gruta. A qualidade do questionário foi testada efetuando um pré-teste que contou com 93 entrevistas em meio a um público de cerca de 200 pessoas durante um concerto musical ocorrido na gruta no dia 23 de junho de 2013.

Considerando a inexistência de informações sobre a população a ser amostrada optou-se por utilizar o método de amostragem não probabilística, que corresponde na aplicação de um número máximo de questionários, em um determinado período de tempo. Este método estabelece que, quando não se 
conhece as características da população e a consequente variância associada a ela, a seleção dos elementos da população para compor a amostra dependerá ao menos em parte do julgamento do pesquisador ou do entrevistador no campo (MATTAR, 2012).

A pesquisa com os usuários da gruta foi realizada in loco de agosto a outubro de 2013, exclusivamente aos sábados e domingos, dias em que a gruta se encontrava aberta à visitação. Ao longo dos três meses de vigência da pesquisa foram aplicados 127 questionários. Somente visitantes com idade mínima de 18 anos foram convidados a participar da entrevista para preencher informações sobre renda mensal. A realização das entrevistas contou com o auxílio de uma equipe devidamente treinada para este fim.

A pesquisa com os moradores de Curralinho, por sua vez, foi realizada na comunidade durante o mês de setembro de 2013. Na área urbana de Curralinho existem 128 domicílios (IBGE, 2010). Considerando que muitos domicílios não havia moradores devido ao uso ocasional ou inexistente, foi possível entrevistar 47 moradores de diferentes domicílios (cerca de $20 \%$ dos moradores locais). O questionário aplicado também buscou identificar as características socioeconômicas do morador, os objetivos e a frequência com que visita a gruta, a expectativa com relação aos benefícios que a gruta pode trazer para a comunidade e a disposição em pagar pela conservação da gruta.

\section{Resultados e discussão}

A análise descritiva dos dados obtidos nas entrevistas permitiu o reconhecimento de percepções e do perfil socioeconômico dos visitantes e moradores do entorno da Gruta do Salitre (Tabela 1). A comparação de alguns parâmetros avaliados revelou informações importantes para a gestão da gruta. A existência de grupos com perfis distintos, mas igualmente maioritários em quantidade de pessoas, por exemplo, exige um planejamento de produtos e serviços adequados às características físicas e psicológicas de cada grupo. Isto se aplica em relação ao domínio semelhante da condição de "casados" e "solteiros" verificada nos dois grupos. Em geral, os visitantes solteiros são mais aventureiros, enquanto os casados, muitas vezes acompanhados da família, preocupam-se mais com a segurança.

A faixa etária, por outro lado, caracterizou uma diferença acentuada entre os dois grupos. Enquanto o grupo dos visitantes é composto principalmente por jovens adultos com idade entre 26 a 35 anos (33\% dos entrevistados), o grupo dos moradores destacou $50 \%$ de entrevistados com idade acima dos 50 anos. Segundo Paula et al. (2008), é importante ressaltar as condições restritivas de visitação a muitas cavidades subterrâneas, considerando as escadarias com muitos degraus irregulares no percurso que normalmente impõem dificuldades para pessoas de maior idade e ou com dificuldades locomotoras. O cuidado com a acessibilidade, neste caso, trata-se de um importante requisito para permitir que muitas pessoas de maior faixa etária possam visitar o local, ao se sentirem seguros para conhecer e retornar sempre que desejarem. 
Tabela 1: Número e percentual de visitantes e moradores da comunidade de Curralinho (Diamantina, MG) entrevistados de acordo com o_gênero, estado civil, faixa etária, renda mensal e escolaridade.

Table 1: Number and percentage of visitors and residents of Curralinho community (Diamantina, MG, Brazil) surveyed according to gender, marital status, age, monthly income and education.

\begin{tabular}{lcc}
\hline Gênero & lisitantes & Moradores de Curralinho \\
Homens & $61(48 \%)$ & $16(34 \%)$ \\
Mulheres & $66(52 \%)$ & $32(66 \%)$ \\
Estado civil & & \\
Casado (a) & $46(36 \%)$ & $21(44 \%)$ \\
Solteiro (a) & $47(37 \%)$ & $16(34 \%)$ \\
Divorciado (a) & $8(6 \%)$ & $4(8 \%)$ \\
Viúvo (a) & $1(1 \%)$ & $5(10 \%)$ \\
Não responderam & $25(20 \%)$ & $2(4 \%)$ \\
Faixa etária & & \\
18 a 25 anos & $22(33 \%)$ & $6(12 \%)$ \\
26 a 35 anos & $42(17 \%)$ & $8(17 \%)$ \\
36 a 50 anos & $35(28 \%)$ & $10(21 \%)$ \\
Acima de 50 anos & $28(22 \%)$ & $24(50 \%)$ \\
Renda Mensal & & \\
Até 3 salários & $38(30 \%)$ & $41(85 \%)$ \\
Entre 3 e 5 salários & $25(20 \%)$ & $5(11 \%)$ \\
Entre 5 e 10 salários & $25(20 \%)$ & $1(2 \%)$ \\
Acima de 10 salários & $28(22 \%)$ & - \\
Não responderam & $11(8 \%)$ & $1(2 \%)$ \\
Escolaridade & & \\
Analfabeto & - & $5(10 \%)$ \\
Ensino básico & $3(2 \%)$ & $30(63 \%)$ \\
Ensino médio/técnico & $29(23 \%)$ & $12(25 \%)$ \\
Ensino superior & $95(75 \%)$ & $1(2 \%)$ \\
\hline Total de entrevistados & 127 & 48 \\
\hline
\end{tabular}

Outra diferença acentuada constatada entre os grupos corresponde à renda mensal. No grupo dos visitantes, ocorreu uma distribuição semelhante no número de entrevistados que se enquadram em cada faixa de renda estipulada. Diferentemente, a maioria das famílias que vivem em Curralinho (85\%) recebem em média até 3 salários mínimos por mês. Esse também é um importante registro para o planejamento dos produtos e serviços envolvendo a gruta, pois reforça a constatação de grupos com perfis diversificados com semelhante número de pessoas no caso de visitantes, e a concentração em apenas uma faixa de renda entre os moradores da comunidade vizinha. Deve ser ressaltado, porém, que no questionário aplicado em Curralinho, a pergunta era sobre a renda familiar mensal, enquanto que o questionário aplicado na gruta, a indagação era sobre a renda pessoal mensal do visitante. Além disso, durante as entrevistas muitos moradores de Curralinho alegaram que a renda familiar não atingia um salário mínimo por mês. Isso demonstra a estagnação econômica que, atualmente, vive a comunidade de Curralinho. A baixa oferta de trabalho e renda local tem promovido o abandono de muitas casas, cujos moradores buscam melhores condições de vida nos grandes centros urbanos. Nesse sentido, a estruturação do uso público da Gruta do Salitre pode contribuir para mudar essa triste realidade da comunidade. 
A escolaridade, por sua vez, representa a disparidade mais acentuada observada entre os dois grupos. Enquanto a maioria dos visitantes $(75 \%)$ possui curso superior, a maioria dos moradores de Curralinho (63\%) possui apenas o ensino básico. Essa diferença de escolaridade entre os dois grupos representa um grande desafio para a estruturação da gestão do uso público da Gruta do Salitre. Diante da baixa qualificação da mão-de-obra local, os gestores terão que oferecer diversos cursos de formação e capacitação dos moradores para dar condições deles receberem com qualidade os visitantes que não se satisfazem apenas com a contemplação das paisagens, porque desejam viver experiências mais intensas e obter novos conhecimentos.

\section{O visitante da Gruta do Salitre}

Do total de visitantes entrevistados $93 \%$ eram provenientes de Minas Gerais. Desse universo, $30 \%$ eram da capital, Belo Horizonte, e $23 \%$ eram moradores do próprio município, Diamantina (Figura 3). Esse resultado corrobora com os dados do monitoramento da gruta obtidos ao longo de todo o ano de 2013 e informados pelos gestores, que constataram que a maioria dos visitantes era originária de 70 cidades mineiras $(76 \%)$, destacadamente da comunidade local diamantinense $(21 \%)$ e de Belo Horizonte (21\%), seguido por visitantes de outros 13 estados brasileiros (12\%), principalmente do Rio de Janeiro e São Paulo, e alguns de outros países.

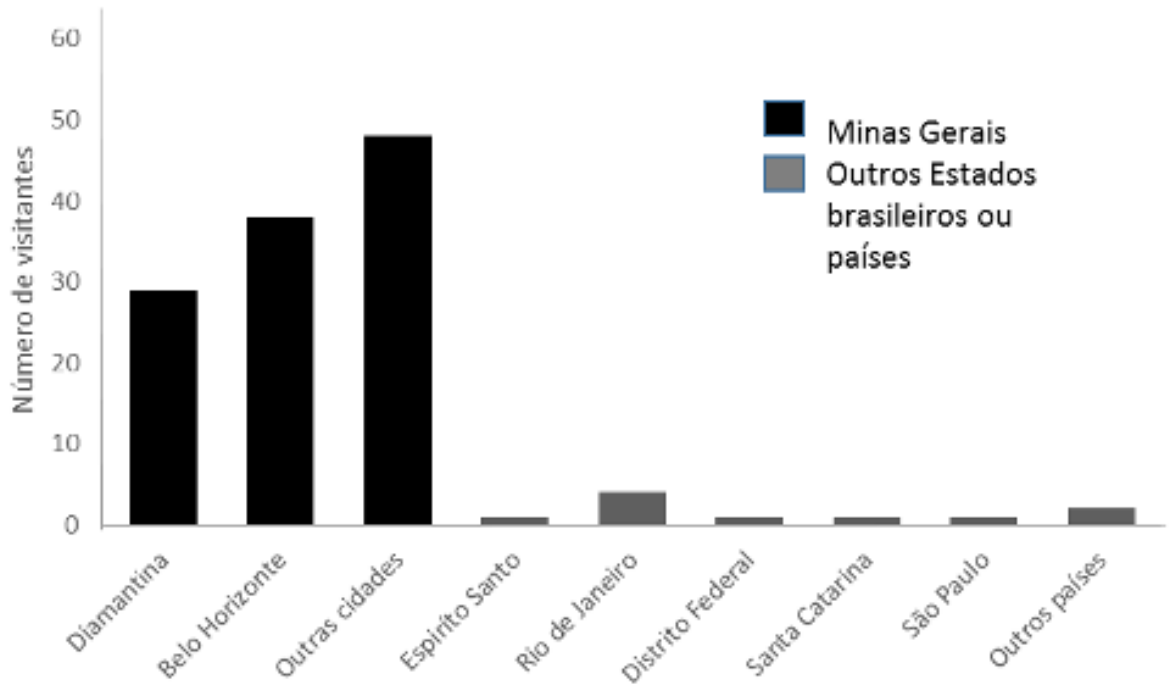

Figura 3: número de visitantes da Gruta do Salitre distribuídos de acordo com os principais locais de origem.

Figure 3: number of visitors from Salitre Cave distributed according to the main places of origin.

Cerca de $70 \%$ dos visitantes visitavam a gruta pela primeira vez. Isto aponta a necessidade de os gestores oferecerem diversas opções de atividades envolvendo a gruta que possam motivar o retorno das pessoas, principalmente dos moradores locais. A principal fonte de informações sobre a gruta foi amigos e/ou parentes para $30 \%$ dos visitantes. Trata-se de um canal interpessoal de divulgação extremamente eficiente em função de diversos fatores, dentre eles, a credibilidade da fonte de informação e a importância da opinião de grupos de referência (MATTAR, 2012). 
No entanto, verifica-se com isso a necessidade de implantação de canais de divulgação em massa da gruta, começando com a confecção de folders contendo basicamente a descrição do atrativo, horários de visitação, localização, imagens e contatos dos gestores. Esse material deveria ser disponibilizado nos meios de hospedagem, agências de turismo e restaurantes, assim como, nas instituições de ensino e pontos comerciais da cidade mais frequentados por moradores locais. Além disso, atualmente é indispensável criar um canal exclusivo de divulgação da gruta na Internet, local onde as mensagens são transmitidas com maior rapidez e possibilita que uma única informação atinja uma audiência de vários milhões de indivíduos.

A maioria dos visitantes (81\%) utilizou o carro próprio como meio de transporte para se locomover até a gruta. Excluindo os visitantes que eram moradores de Diamantina, a maioria permanece acima de dois dias na cidade. Desses visitantes apenas $24 \%$ estavam hospedados em casa de amigos e/ou parentes, os demais utilizam os diversos tipos de meios de hospedagem disponíveis na cidade, como pousada, hotel, albergue e pensão. A distribuição dos visitantes da gruta pelo gasto médio diário com despesas de viagem (hospedagem, alimentação e entretenimento) reforça a existência de públicos distintos que frequentam a cavidade: $11 \%$ gastam até 50 reais/dia; 17\% entre 50 e 100 reais; $20 \%$ entre 100 e 200 reais; 15\% entre 200 e 300 reais; e 6\% acima de 300 reais.

Essas últimas constatações demonstram que é essencial haver a parceria dos gestores da gruta com os empresários do trade turístico local, além do poder público. A singularidade da gruta comprova o seu potencial para receber uma quantidade expressiva de visitantes e, com isso, gerar benefícios socioeconômicos para toda a sociedade. Neste caso, a gestão compartilhada poderá impulsionar a estruturação do atrativo para receber os visitantes com maior segurança e qualidade, bem como assegurar a conservação do patrimônio natural.

Em relação à opinião dos visitantes sobre aspectos importantes que envolvem a gestão do uso público da gruta, verificou-se que atualmente o atendimento dos monitores é o item melhor avaliado, por outro lado, a sinalização, a infraestrutura e as condições de acesso da gruta são questões que precisam ser melhoradas (Figura 4). E por fim, sobre o grau de satisfação das pessoas com relação à experiência na gruta, $54 \%$ dos visitantes declararam que a visita atendeu plenamente as suas expectativas, $86 \%$ estão dispostos a visitar a gruta novamente, e $91 \%$ indicaria a gruta para visitação de parentes e amigos (Figura 5). Além disso, $81 \%$ dos visitantes enfatizaram a grande importância da gruta para o turismo local.

O elevado grau de satisfação das pessoas com a visita a Gruta do Salitre, mesmo o local não dispondo de infraestrutura adequada, demonstra a dimensão do seu potencial turístico. Vale chamar a atenção que de acordo com os gestores, embora a gruta seja bastante frequentada por turistas, a maioria deles não aproveita a oportunidade para conhecer Curralinho. Isto justifica fortemente a necessidade de projetos de investimentos públicos e privados com o intuito de assegurar a conservação ambiental, melhorar a qualidade da experiência dos visitantes, e gerar maiores benefícios socioeconômicos para a comunidade vizinha. 


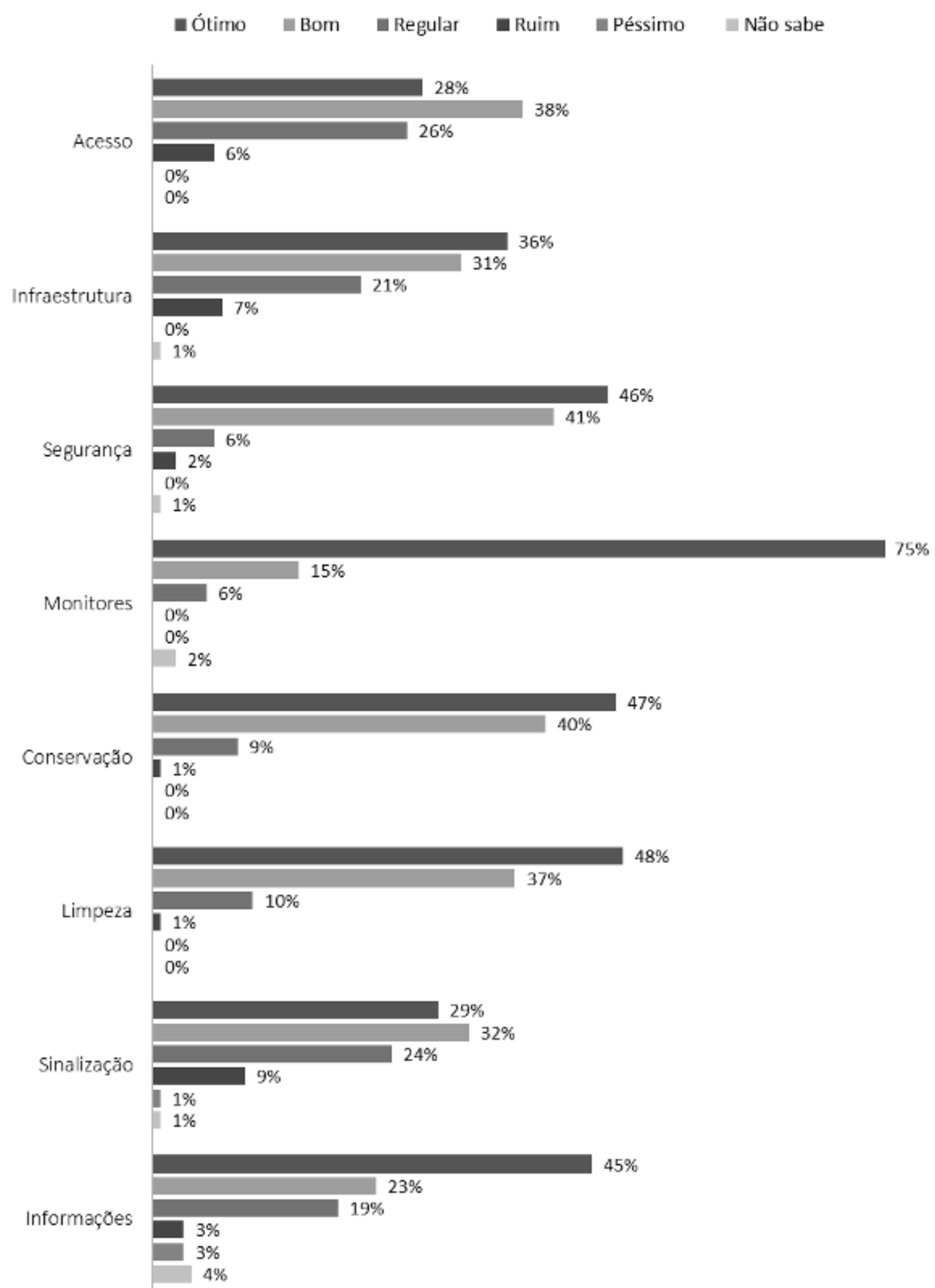

Figura 4: avaliação dos visitantes (percentual) em relação aos diversos aspectos que envolvem a gestão do uso público da Gruta do Salitre.

Figure 4: evaluation of visitors (percentage) on the various aspects involved in the management of public use of Salitre Cave. 


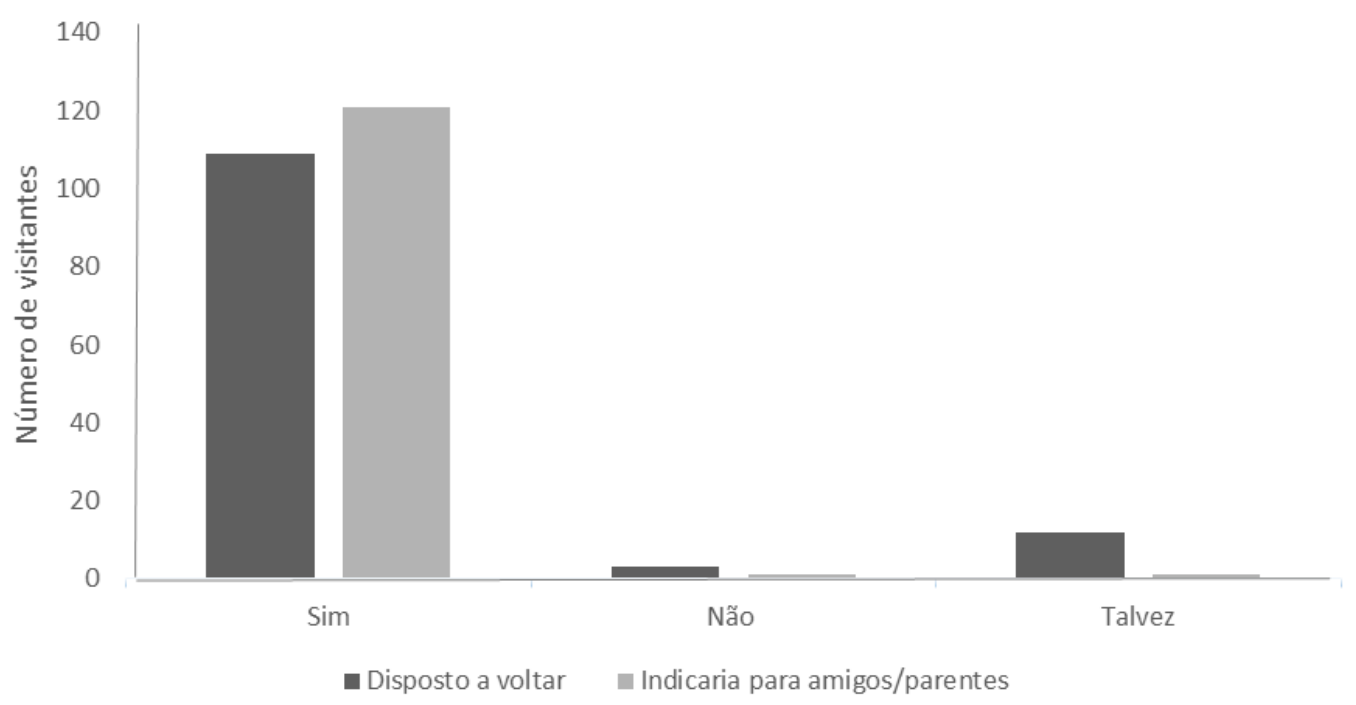

Figura 5: número de visitantes distribuídos pelo grau de satisfação com relação à experiência na Gruta do Salitre, manifestado pelo interesse de voltar ao atrativo natural e de indicá-lo para visitação de outras pessoas.

Figure 5: number of visitors divided by the degree of satisfaction with the experience in the Salitre Cave, manifested the interest to return to the natural attraction and point it out to visitors from other people.

\section{O morador de Curralinho}

Entre os moradores de Curralinho entrevistados, $48 \%$ deles não nasceram na própria comunidade, todavia, $64 \%$ desses que não são de origem local vivem por lá há mais de 16 anos. Com relação à ocupação profissional, 21\% dos entrevistados são "donas de casa", responsáveis pelos afazeres domésticos. Uma parte delas tem como fonte de renda a aposentadoria ou pensão do Governo. Dos demais moradores, $17 \%$ alegou exercer atividade remunerada temporária, $11 \%$ que trabalha com carteira assinada, $9 \%$ são funcionários públicos, $4 \%$ estão desempregados e, apenas $2 \%$ era estudante. Segundo Santos; Araújo et al. (2015), a falta de qualificação da mão-de-obra local de Curralinho reflete diretamente nas atividades remuneradas exercidas pelos moradores e, por conseguinte, na renda mensal das famílias. A falta de oportunidades de trabalho é o problema que mais atormenta os moradores de Curralinho, com a afirmação de $55 \%$ dos entrevistados relatando haver pessoas desempregadas na família. Desses, $54 \%$ declarou haver mais de uma pessoa na família sem emprego.

Em relação à visitação na Gruta do Salitre, verificou-se que $87 \%$ dos moradores já tinham visitado a cavidade. Entre aqueles que não a conheciam, 3 alegaram a falta de interesse, e outros 3 a falta de oportunidade. Entre os moradores que já conheciam a gruta, $97 \%$ manifestaram interesse de visitá-la novamente, e entre o total de entrevistados, $96 \%$ indicaria a cavidade para visitação de amigos e parentes.

Em relação às expectativas com a Gruta do Salitre, 92\% dos moradores acreditam que a gruta pode contribuir para melhorar as condições de vida da 
comunidade, sobretudo, impulsionando a atividade turística local. Para eles, o turismo pode contribuir para a melhoria da qualidade de vida, especialmente, através da geração de emprego e renda. Para isso, é fundamental a participação da comunidade no processo de estruturação do turismo, uma vez que são os moradores locais quem devem ser os principais beneficiários. No entanto, a falta de integração e participação dos moradores é justamente o principal empecilho para desenvolvimento de projetos deste tipo na comunidade (SANTOS; ARAUJO, 2014).

Para encerrar, foi solicitado uma avaliação do trabalho realizado pelos gestores locais em prol da estruturação da gestão do uso público da gruta. A maioria dos moradores avaliou o trabalho como sendo bom (45\%) ou ótimo (28\%). Entretanto, verificou-se que $23 \%$ dos moradores entrevistados ainda desconhece o trabalho do Instituto Biotrópicos (Figura 6), apontando a necessidade de realização de mais campanhas de sensibilização da comunidade para garantir o apoio dos moradores e mobilizar um contingente maior de pessoas que deseja se inserir no processo de estruturação do uso público da gruta.

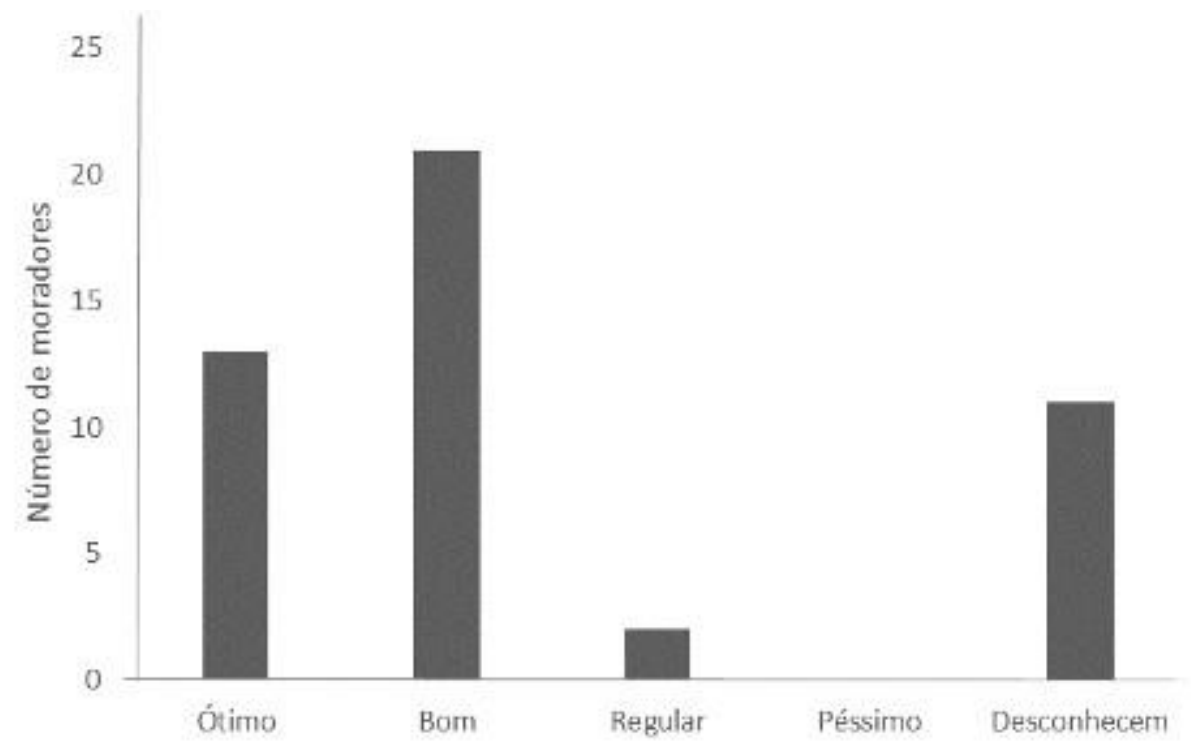

Figura 6: número de moradores de Curralinho, distribuídos de acordo com a avaliação pessoal sobre a gestão do uso público da Gruta do Salitre.

Figure 6: number of Curralinho residents, distributed according to personal evaluation on the management of public use of Salitre Cave.

\section{Disposição a pagar pela conservação da Gruta do Salitre}

Em relação à indagação sobre a disposição a pagar um valor anual hipotético para conservação da gruta, $47 \%$ dos visitantes alegou interesse enquanto outros declararam não estarem dispostos a pagar $(50 \%)$ ou não responderam $(3 \%)$. Por outro lado, entre os moradores de Curralinho $68 \%$ afirmou disposição a pagar pela conservação da gruta. Observa-se que tanto visitantes dispostos e indispostos a pagar pela conservação da gruta ficou em torno de $50 \%$. Ao contrário disso, a maior parte dos moradores de Curralinho demonstrou interesse em contribuir financeiramente, ainda que as rendas mensais e o nível de escolaridade desse 
grupo sejam demasiadamente menores em relação à dos visitantes, conforme apresentado e discutido acima.

O percentual de moradores de Curralinho dispostos a pagar pela conservação da Gruta do Salitre ficou acima do percentual de moradores de Tiradentes/MG $(61 \%)$, dispostos a pagar pela conservação da área de proteção ambiental local Serra de São José, e equiparado ao percentual de moradores de Rio Branco/AC (69\%) dispostos a contribuir para conservação do Parque Ambiental Chico Mendes (PEREIRA; CAMPOS, 2006; SILVA, 2003). Pode-se perceber que, em geral, a maioria das pessoas que vivem próximas a determinado sítio natural apresenta-se mais disposta a contribuir financeiramente com a sua conservação. No caso específico da Gruta do Salitre, ficou evidenciado nesse estudo que isso se deve ao fato da crença dos moradores de Curralinho de que a cavidade pode contribuir com a melhoria das condições de vida da comunidade.

Com relação aos visitantes, não houve predominância de nenhum dos grupos dispostos e não dispostos a pagar pela conservação da gruta. O percentual de visitantes dispostos a pagar (47\%) é semelhante aos resultados obtidos por outros estudos de valoração econômica de áreas naturais, como o do Parque Metropolitano de Pituaçu, Salvador/BA, que identificou que 55\% dos visitantes estavam dispostos a pagar pela conservação (SOUSA \& MOTA, 2006), e o do Bosque do Alemão,

Curtitiba/PR, em que $62 \%$ dos visitantes entrevistados estavam dispostos a pagar um valor para a conservação (HILDEBRAND et al., 2002). No estudo de valoração da área cárstica da região de Maros, na Indonésia, 66\% dos visitantes estavam dispostos a pagar pela conservação do local (WALUYO, 2005).

Dentre os moradores que não estão dispostos a pagar pela conservação da Gruta do Salitre, 67\% alegou que restrições econômicas os impediam de contribuir. Justificativa preponderante com base nas características socioeconômicas da comunidade apresentadas anteriormente. No entanto, $48 \%$ dos visitantes indispostos a pagar justificou a sua posição por considerar que esta seja uma função que compete ao governo. Segundo Silva (2003), em situações como essa o indivíduo tira de si qualquer responsabilidade sobre o uso de um ativo ambiental e a transfere para o poder público. O problema, nesse tipo de atitude, reside no fato dessa postura incentivar a sociedade a ficar fora do processo de tomada de decisão sobre o gerenciamento dos recursos naturais. Sendo que, o gerenciamento desse tipo de recursos influencia, diretamente, a qualidade de vida da sociedade presente e das futuras gerações.

\section{Conclusões}

O conhecimento das percepções e do perfil socioeconômico dos visitantes e da comunidade vizinha ao atrativo natural Gruta do Salitre sinalizou importantes informações para serem consideradas no planejamento da gestão do uso público local. O banco de dados completo e a devida utilização dessas informações pelos gestores, bem como pelo trade turístico podem efetivamente contribuir com 0 desenvolvimento do espeleoturismo local através da promoção de produtos e 
serviços adequados aos diferentes públicos alvo que frequentam o atrativo turístico, incentivando a taxa de retorno das pessoas que ainda é muito pequena.

Concomitantemente, espera-se que os esforços em prol da conservação através do ordenamento do uso público da gruta, possam sensibilizar e atrair potenciais parceiros e apoiadores para se alcançar também a reversão da estagnação socioeconômica da comunidade de Curralinho oferecendo opções de trabalho e renda para os moradores locais, gerando benefícios para toda a sociedade.

\section{Referências bibliográficas}

ARAUJO, H.R.; OLIVEIRA JÚNIOR, A.F.; AZEVEDO, A.A. Valoração de serviços ambientais: subsídio para a sustentabilidade do atrativo natural Gruta do Salitre, Diamantina, Minas Gerais. Pesquisas em Turismo e Paisagens Cársticas, 8(1), 2015. no prelo.

ARAUJO, H.R.; OLIVEIRA JÚNIOR, A.F.; AZEVEDO, A.A. Caracterização dos serviços ambientais prestados pela Gruta do Salitre. In: Congresso de Natureza, Turismo e Sustentabilidade, 3., 2013, Bonito. Anais... Bonito, 2013. p. 101-106.

AZEVEDO, A.A.; ARAUJO, H.R. Processo de estruturação da gestão do uso público da Gruta do Salitre, Diamantina, Minas Gerais. In: Congresso Brasileiro de Espeleologia, 31., 2011, Ponta Grossa. Anais... Ponta Grossa, 2011. p.201208.

AZEVEDO, A.A; GOULART, M.F; SILVA, J.A.; VILHENA, C.F. 2009. Mosaico de Unidades de Conservação do Espinhaço: Alto Jequitinhonha-Serra do Cabral: processo de criação e implantação. Relatório técnico. Diamantina: Instituto

Biotrópicos. 55p. Disponível em:

$<$ http://www.icmbio.gov.br/portal/images/stories/mosaicos/planejamentoespinhaco.pdf >. Acesso em 14 de abr. 2015.

BAGGIO, H; RODRIGUES, F. C; TRINDADE, W. M. Morfologia Cárstica do Maciço Quartzítico da Gruta do Salitre, Diamantina-MG. Caminhos de Geografia, v. 13, n. 43, 2012.

BRANDÃO, J.M. Grutas turísticas: patrimônio, emoções e sustentabilidade. Geonovas, n. 22, p. 35-43, 2009.

BRASIL. Constituição da República Federativa do Brasil de 1988. Disponível em: $<$ http://www.planalto.gov.br/ccivil 03/constituicao/constituicaocompilado.htm>. Acesso em: 30 de nov. 2014

CECAV - CENTRO NACIONAL DE PESQUISA E CONSERVAÇÃO DE CAVERNAS. Base de dados geoespacializados das cavernas do Brasil. 2015. Disponível em: <http://www.icmbio.gov.br/cecav/downloads/mapas.html>. Acesso em: 01 de abr. 2015.

CECAV - CENTRO NACIONAL DE PESQUISA E CONSERVAÇÃO DE CAVERNAS. Plano de Ação Emergencial para o uso Público da Gruta Salitre, Diamantina- MG. 2p. 2011.

CIGNA, A; BURRI, E. Development, management and economy of show caves. International Journal of Speleology, Bologna, v.29, n.1, p.1-27, 2000. 
CONAMA - CONSELHO NACIONAL DO MEIO AMBIENTE. Resolução CONAMA n³47 de 10 de setembro de 2004. Diário Oficial da União, Brasília, ed.176, seção 01 , p.54. 13 set. 2004.

FIGUEIREDO, L.A.V; RASTEIRO, M.A.; RODRIGUES, P.C. Legislação para a proteção do patrimônio espeleológico brasileiro: mudanças, conflitos e o papel da Sociedade Civil. Espeleo-Tema, Campinas, v. 21, n. 1, p. 49-65, 2010.

GUERRERO, P. Vale do Jequitinhonha: a região e seus contrastes. Revista Discente Expressões Geográficas, Florianópolis, n. 5, p.81-100, 2009. HILDEBRAND, E.; GRAÇA, L; HOEFLICH, V. "Valoração contingente" na avaliação econômica de áreas verdes urbanas. Florestas, v. 32, n. 1,p. 121132, 2002.

JANSEN, D.C; CAVALCANTI, L.F; LAMBLÉM, H. S. Mapa de potencialidade de ocorrência de cavernas no Brasil, na escala de 1: 2.500. 000. Revista Brasileira de Espeleologia, v. 1, n. 2, p. 42-57, 2012.

KARMANN, I; SALLUN FILHO, W. Paisagens subterrâneas do Brasil. Ciência Hoje, São Paulo, v. 40, n. 235, p. 18-25, 2007.

MATTAR, F. Pesquisa de Marketing. 5. Ed. Rio de Janeiro: Elsevier, 2012.

MMA - Ministério do Meio Ambiente. Portaria 444 de 26/11/2010. Brasília, DF.

NEVES, C.C.; REZENDE, S. Aspectos sócio-demográficos do município de Diamantina na transição da atividade mineradora para as atividades turística educacional. Departamento de Engenharia Sanitária e Ambiental da UFMG, 2006.

NOGUEIRA, M.D.P. Pólo Jequitinhonha - 10 [1996 - 2006]: a consolidação de experiência de desenvolvimento regional. Belo Horizonte: UFMG/PROEX, 2008.

PEREIRA, P.F.S; CAMPOS, E.M.G. Valorando o ecoturismo e as atividades recreacionais da área de proteção ambiental serra de São José (MG): uma aplicação do método custo de viagem e da valoração contingente. Anais do XII Seminário sobre a Economia Mineira. Diamantina, 2006. Disponível em:

$<$ http://www.cedeplar.ufmg.br/seminarios/seminario diamantina/2006/D06A081. pdf >.

Acessado em: 28 de novembro de 2013.

SAADI, A. A geomorfologia da Serra do Espinhaço em Minas Gerais e de suas margens. Geonomos, v. 3, n. 1, p. 41-63, 1995.

SANTOS, E.R.; ARAUJO, H.R. O turismo na visão dos moradores de uma comunidade garimpeira: o caso de Extração (Curralinho), Diamantina, Minas Gerais. Revista Cenário, v. 2, n. 3, p. 153-169, 2014.

SECTUR - Secretaria Municipal de Cultura, Turismo e Patrimônio de Diamantina Plano de Inventário de Diamantina. 2010.

SILVA, R.G. Valoração Contingente do Parque "Chico Mendes": uma Aplicação Probabilística do Método Referendum com Bidding Games.2003. 125 f. Dissertação Pós-Graduação em Economia Aplicada da Universidade Federal de Viçosa. Viçosa, 2003.

SILVEIRA, C.E.; MEDAGLIA, J. Perfil da Demanda Turística Real de Diamantina e Região: Características de Viagem, Motivações, Percepções \& Expectativas. Relatório Final de Pesquisa. Departamento de Turismo da Universidade Federal dos Vales do Jequitinhonha e Mucuri, 2014. 
SOUSA, G.B; MOTA, J.A. Valoração econômica de áreas de recreação: o caso do Parque Metropolitano de Pituaçu, Salvador, BA. Revista de Economia, UFPR, v. 32, n. 1, p.37-55, 2006.

UNESCO/MaB - Organização das Nações Unidas para a Educação, a Ciência e a Cultura. Programa Man and the Biosphere. 2005.

WALUYO, H; SADIKIN, S.R; GUSTAMI; WHITING, P. An economic valuation of biodiversity in the karst area of Maros, south Sulawesi, Indonesia. Biodiversity, v. 6, n.2, p. 24-26, 2005.

\section{Agradecimentos}

À Universidade Federal de Ouro Preto (UFOP) que conferiu bolsa ao primeiro autor para desenvolvimento desde trabalho como parte de sua dissertação de Mestrado apresentada ao Programa de Pós-graduação em Sustentabilidade Socioeconômica Ambiental. Ao Prof. Guilherme Varajão (Universidade Federal dos Vales do Jequitinhonha e Mucuri) pelo auxílio na elaboração do mapa de localização da Gruta do Salitre. Aos voluntários que auxiliaram a aplicação dos questionários e a coleta de informações para a condução desta pesquisa.

Hugo Rodrigues Araújo: Universidade Federal de Ouro Preto, Ouro Preto, MG, Brasil.

E-mail: hugo@biotropicos.org.br.

Link para o currículo Lattes: http://lattes.cnpq.br/9305503365859375

Arnaldo Freitas Oliveira Júnior: Centro Federal de Educação Tecnológica de Minas Gerais, Belo Horizonte, MG, Brasil.

E-mail: arnaldo@deii.cefetmg.br.

Link para o currículo Lattes: http://lattes.cnpq.br/2754961037728092

Alexsander Araújo Azevedo: Instituto Biotrópicos, Diamantina, MG, Brasil.

E-mail: alex@biotropicos.org.br.

Link para o currículo Lattes: http://lattes.cnpq.br/0416232251987206

Data de submissão: 28 de abril de 2015

Data de recebimento de correções: 09 de junho de 2015

Data do aceite: 09 de junho de 2015

Avaliado anonimamente 